\title{
Modeling cognitive learning spaces in Russian universities in the context of globalization and digitalization
}

\author{
Tatiana Tregubova ${ }^{1 *}$, Irina Ainoutdinova ${ }^{2}$ \\ ${ }^{1}$ Institute of Pedagogy, Psychology and Social Problems, 420039, Isaeva str., 12, Kazan, Russia \\ ${ }^{2}$ Kazan (Volga region) Federal University, 420008, Kremlevskaya, str., 18, Kazan, Russia
}

\begin{abstract}
The article is devoted to the modeling cognitive learning spaces in Russian universities for the effective training of students and their preparation for life and future profession. Based on a comparative analysis of theoretical and practical approaches to the problem by Russian and foreign scientists, a conclusion is made about the importance and relevance of the topic for academic community and society as a whole. In modern conditions, the processes of globalization, integration, informatization and digitalization induce universities to change the vector of their activities in the direction of technology and innovation, advanced forms of communication and mental interaction, technological methods of teaching and knowledge transfer, and, as a result, cause them to review their learning spaces as well. From a pedagogical perspective, the design of cognitive learning spaces may equally influence the entire educational landscape of the country as well as the learning climate of a particular institution, learning outcomes of a particular student and the system of professional development of a particular teacher and/ or researcher in multiple ways. The purpose of this work is to study and analyze the current state of the problem, systematize and concretize the conceptual apparatus, identify current positive trends in higher education allowing to model and design the effective tech-based, information-rich and equitable cognitive learning space at university, which will provide a beneficial learning environment with regard to mental needs and expectations of modern students.
\end{abstract}

\section{Introduction}

Today, the search for optimal models of cognitive learning spaces of universities correlates with the need of society for the development of innovative education, oriented towards the future and based on the training of competitive specialists and the development of citizens who are harmonious in their professional, intellectual, cultural and moral sense. When modeling and organizing learning spaces, universities should take into account not only the

\footnotetext{
${ }^{*}$ Corresponding author: tmtreg@,mail.ru
} 
challenges of our time, but also the historical stages, entire set of acquired experience and most common patterns of social development of the country. In this regard, it is necessary to find a compromise between the well-established traditions of fundamental university education and the emerging trends associated with Russia's entry into the global educational environment along with the ongoing processes of globalization, integration, informatization and digitalization, which have a deep impact on many internal processes $[1,2,3]$.

As experience shows, the concepts of "educational space" and "educational environment" are used quite often and interchangeably for interpretation of various formal characteristics of effective teaching and learning processes, namely the characteristics of teachers and students; teaching and learning objectives; teaching strategies and activities supporting learning; assessment strategies that stimulate and measure learning outcomes; cultural context that directly affects teaching and learning, etc. [3]. In the scientific and educational literature, these terms are widely used both to characterize the diverse physical locations, contexts and cultures in which students learn, and to refer to individual learning settings that can be equally attributed to the physical place in which teaching and learning occurs as well as to the learning needs and learning styles of modern Gen Z students [4].

For example, the global educational space or environment - unites the national educational systems of different countries, varying in the types of structure and level of development [5]. These educational systems differ significantly in their historical, philosophical and cultural origins and traditions, the level of goals, objectives, methods and technologies of teaching, as well as in the variety of approaches to assessing quality and in difference of responses to the challenges of the time, including latest trends in education. UNESCO, as the United Nations specialized agency for education, science and culture, carries out organizational and legal regulation of the development of the global educational space, taking into account the need to preserve the diversity and identity of each subject [6]. It develops international legal acts and standards, both global and regional, for all countries in order to promote flexibility, openness and access to resources in any remote corner. In particular, UNESCO prepared standards for the competences of teachers in the use of ICT (Information Communication Technologies) [7], and formulated five core competencies for the personal growth of each individual, including political, social, intercultural and communicative competencies, as well as those associated with the emergence of the information society allowing to realize the ability and desire to learn and develop [8], etc.

Likewise, the so called European Higher Education Area (EHEA) unites the educational systems of different countries. The joint educational environment is a unique international project based on collaboration in higher education and the result of the political will of 49 European countries with different political, cultural and academic traditions. EHEA was created and became a reality in March 2010, during the Budapest-Vienna Ministerial Conference as an integral part of the Bologna Process, which in its turn was launched in 1999, Russia having joined it as early as in 2003 [9]. EHEA implements a common set of commitments (structural reforms and shared tools) and promotes common key values, such as freedom of expression, autonomy for institutions, independent student unions, academic freedom, free movement of students and staff. Gradually, over the past twenty years, EHEA has done much to create and develop a truly effective area that provides more comparable, compatible and coherent systems of quality higher education throughout Europe [10].

A single educational space or environment of Russia represents the entire set of educational institutions of various types on the territory of the Russian Federation as well as stakeholders. The area also encompasses all public and state organizations interacting with institutions and stakeholders, as well as the teaching and learning processes themselves being regulated by the Federal Law "On Education" (N 273-FL of 12.21.2012) and other regulatory documents designed to provide variability albeit a common structure of curricula and content of educational programs based on the federal educational standards [6]. Here 
we can single out the regional educational space or environment, which is geographically localized within the boundaries of one of 85 constituent entities of the Russian Federation (republics, territories, regions, cities of federal significance, autonomous regions and autonomous districts). These areas can partially function within the framework of their regional laws and regulations, but at the same time, they shall comply with the standards, laws and mechanisms proposed by the unified educational space or environment of Russia.

When we think about learning spaces, we often imagine educational institution and its physical settings as a place in which teaching and learning occur. The term in this respect is commonly used as a more definitive alternative to "classroom," though it may also refer to some indoor or outdoor locations, either actual or virtual. We have to admit that the definition of learning spaces has become broader and much more inclusive over the past decades $[3 ; 11]$. The current processes of globalization, integration, informatization and digitalization have changed our perception of many axiologies (values), meanings and ontologies (ways of being) [12] and led to the need to rethink old ideas about learning spaces. Likewise, the entirely different "digital generation $Z$ " students are also inspiring new concepts of learning spaces. Through the use of information technology (IT) and appropriate adaptive methods, techniques and resources, today's learning spaces have the potential to serve a new learning paradigm while meeting the mental needs and digital expectations of learners who have grown up using computers and other networked devices. Thus, the learning space of a particular institution should be a multi-component, multi-level and multimodal system. It will include not only a separate institution such as a school, university, or research center with the administrative department, teaching staff, furniture, equipment, aids and resources, etc. But it should reflect specific set of goals, objectives and conditions for successful teaching and learning, thus encouraging learners to think more deeply and independently, to model their own unique learning paths for optimal learning outcomes, to engage into the active transfer and acquisition of knowledge, which will enable them to create new connections, interactions, meanings and understandings $[11 ; 13]$.

In this respect, the learning space of an individual should also be noted. In addition to the space or environment covering learning demands, it will also include real life experience, personal or private space and individual personal characteristics and habits [14]. Together, they are aimed at meeting a person's needs for social, intellectual (cognitive), cultural and moral development, deepening and expanding the learning needs and styles aimed at improving professional qualifications, communication skills, social status, etc. [15].

Summarizing the above said, we can assume that the concepts of "learning space" and "learning environment" can be understood in terms of completely different approaches, objects and subjects of educational reality, although together they represent a structured hierarchical system in all the variety of its properties and characteristics (openness, humanism, availability, accessibility, flexibility, sustainability, innovation, technology, etc.); current conditions and world order (globalization, integration, informatization, digitalization, standardization, society's demand for new professions and professionals, the consequent need to improve the quality of higher education, individual and social diversity, etc.); functions (training, upbringing, education, development, communication, etc.); levels (global, European, national, regional, institutional and individual) and directions (vectors or strategies) of activity (normative, perspective, active, communicative, informative, etc.) [6].

For the purposes of our research, we examined best models of cognitive learning spaces specially designed to meet the mental needs and digital expectations of university students. We regarded cognitive learning as an active, constructive and long-term process aimed to help students explore and understand how ideas are retrieved and connected in order to deeply process information, transfer and apply it to new situations and relevant contexts [1].

\section{Methods}


The methodological framework of this research work rests on the set of social, pedagogical, integrative, competence and comparative approaches, covering all aspects of both teachers' and students' academic activities, including the process of professional training in the context of globalization, integration, informatization and digitalization [1-6, 9]. To determine how internal and external factors can influence the mental processes of individual students and beneficially complement their active learning practice, we based our research on some recognized cognitive learning theories. The theory of cognitive development by Jean Piaget [16] recognized the huge role of the external environment, which can influence the internal cognitive structure of people. His theory focused not only on examining how people acquire knowledge, but also on understanding the nature of their intelligence and stages of their mental (cognitive) development [16]. Several researchers have made significant contributions to this theory. For example, the American psychologist Jerome Bruner [17] focused on how mental processes are linked to teaching and learning.

The other approach that deserves attention is based on the social cognitive theory (SCT), which started as the social learning theory (SLT) proposed in the 1960s by Albert Bandura [18]. The theory states that individual behavior is influenced by social interactions, the experiences of others, and the mass media. It helps to generally understand how people are influenced by external factors and how their internal state may affect the environment. One of the major components of SCT is observational learning, which offers both positive and negative modes of behaviors that will accordingly influence the behavior of the observer. The SCT is composed of four processes of goal realization: self-observation (based on regularity and proximity); self-evaluation (affected by standards and importance of the goals); self-reaction (prompted by both positive and negative progress); and selfefficacy (supported by the belief or the likelihood of goal completion). These components are interrelated and all have an effect on learning motivation and goal attainment [19].

Another theory of interest is cognitive behavioral theory (CBT) that describes how people's perceptions, thoughts, external factors or situations influence their emotional, behavioral and often physiological reactions. This theory was pioneered by the American psychiatrist Dr. Aaron T. Beck in the 1960s [20]. This approach mainly refers to the mental processes of a person, such as the thoughts and interpretations of life events; so, it focuses on the internal processes of learning rather than on the observed behavior in the learning settings. Sociocultural theory by Lev Vygotsky [21], on the contrary, asserts that learning is based on interaction with other people and, therefore, individual higher-order functions can only develop in appropriate cultural context. Vygotsky`s concept of a zone of proximal development is also important since teachers can use it as a guide for student achievement.

The latest information processing theory (IPT) by Richard Hall is based on the idea that humans actively process any information like a computer [22]. This tech-based approach reveals the gradual stages in information processing by individuals, namely, encoding (collecting and representing information); storage (holding necessary information); retrieval (obtaining information when needed); and a management/control process that defines how, when and for what purpose the acquired information will flow through a separate system.

In order to identify best teaching strategies that may be used to improve learners' ability to process information deeply and meaningfully we studied the unique characteristics of modern students often attributed to "digital generation Z" [23]. Various types of cognitive learning patterns have been examined with due diligence too. We identified about 15 applicable practices that are already quite popular with innovative teachers, e.g., associative, discovery, experiential, observation or imitation learning, metacognitive strategies, etc. [24]. Multiple cognitive tools and educational technologies that help students learn and think deeply have been tested for their applicability, availability, and safety during the research.

\section{Results and discussions}


The main result of the research is the development of a model of an efficient, technologybased, information-rich, and equitable university space based on the active, constructive and long-term paradigm of teaching and learning, aimed, on the one hand, to help teachers realize their professional potential and, on the other hand, to provide students the opportunity to learn and understand how to maximize their cognitive capabilities [25]. The outdated patterns of rote memorization of facts can hardly help students understand how to use information they have learned and apply it to new situations. It is evident that acquiring information without giving it a deeper meaning and understanding, makes learning process practically useless and its outcomes worthless [22]. Cognitive learning strategies, on the contrary, allow learners to form and develop their ability to process various chunks of information deeply, transfer, exchange and apply them to new situations meaningfully [22].

Cognitive learning strategies may equally be used in traditional (face-to-face) format as well as in distance and online educational settings [1,2]. Let us look at the traditional learning space of university as one of the types of institutions of higher education in Russia (along with the institutes and academies). A university, by definition, is an educational institution that implements educational programs of higher education at all levels (from bachelor's to master degrees) in a wide set of knowledge areas (specialties), as well as it provides programs for post-graduate students, retraining and advanced training programs for highly qualified scientific and pedagogical staff. As a rule, in Russia the university also carries out fundamental and applied scientific research in a wide range of sciences and is regarded the leading scientific and methodological center in its field of activity. Many universities operate as educational, scientific and practice-oriented centers. By structure, universities may unite under their roof several institutes or faculties, which represent the totality of various disciplines that create the basis of fundamental scientific knowledge [13].

Based on the definition of university as of the institution of higher education and its traditional learning space, it can be concluded that the learning space of university includes many spaces with different vectors of activity that physically locate in different structural divisions. In reality, university is also a part of a wider social space of a city, region or country, which operates as an open educational continuum in all the diversity and integrity of external and internal factors [26]. The integrity of the space is supported by various institutional, functional, procedural and subject-matter processes that manifest themselves at all its levels and in various settings. The continuity of educational process can be traced outside the university premises, where the traditions of life long and cognitive learning are implemented by highly qualified and motivated specialists - the university graduates [6].

No wonder why we have chosen university grounds to model cognitive learning space for the effective training of students and their preparation for life and future profession [1]. In our vision, such space should be a multi-dimensional, interdisciplinary and multilingual educational area based inter alia on the inclusion of native languages and one or more foreign languages studied by students (English, German, French, Spanish, etc.) [1, 3].This model should function in the interconnection and complementarities of all its components that traditionally exist in the educational settings of university. Cognitive learning space must also be organized in accordance with the changing mental needs and learning styles of today's "digital" students, based on their preferences and capabilities [23]. Teachers should encourage their students to engage in active learning, embrace the learning process, make their own learning paths and form their own connections, meaning and understandings in any discipline as a multitude of axiologies (values) and ontologies (ways of being) [12].

Teachers must support incorporation of a cognitive learning perspective into educational settings as a companion to the course delivery thus giving students a framework of learning strategies and allowing acquisition of knowledge and skills through cognitive process [12]. The main goal of learning strategies is to get students to become learners that are more effective. Research on the topic has shown us plenty of different ways to do that. But the 
three most famous cognitive learning strategies are mnemonic - help students memorize content, like facts or terms; structural - encourage students to mentally pick out important information and put it together into one structure; and generative - help students to incorporate new content into existing knowledge and reach a deeper understanding) [26, 27].

To optimize active learning practice and enhance its positive impact on university-level learners, teachers can choose from a variety of active pedagogical methods that involve students to actively work on learning tasks and reflect on their work, apart from simply listening, watching or taking notes. For these purposes, teachers may also specially design Active Learning Classrooms (ALCs) marked by deliberate architectural or design attributes that are specifically intended to promote active learning. In particular, ALCs shall be equipped with moveable furniture, plentiful of writing surfaces or technological tools [25]. In addition, as most resources used in higher education become digital, delivered over the Internet, and the network connection becomes more portable, these two developments make it possible for learning to happen informally in areas outside the traditional classroom [25].

\section{Conclusions}

1. The idea to model a cognitive learning space in Russian university has been caused by several factors. The current processes of globalization, integration, informatization and digitalization induce universities to change the vector of their activities in the direction of technology and innovation, advanced forms of communication and mental interaction, technological methods of teaching and knowledge transfer, and, as a result, cause them to review their learning spaces as well. The authors of the article, as university professors, certainly support new pedagogical trends or innovations if they are able to provide effective training of students, their preparation and development for life and future profession $[1,6]$.

2. Based on a comparative analysis of theoretical and practical approaches to the problem of cognitive learning by Russian and foreign scientists, a conclusion is made about the importance and relevance of the topic for academic community and society as a whole [19].

3. Cognitive learning is defined as a type of learning that involves active, constructive, and long-term process aimed to engage students in the active learning settings and help them explore and understand how ideas are retrieved and connected in order to deeply process information, transfer and apply it to new situations within the relevant contexts [12].

4. From a pedagogical point of view, the design of an effective cognitive learning space should be based on certain cognitive learning components, namely, comprehension - which allows students to understand the reason or "why" behind a specific topic and how it fits into a larger knowledge; memory - which enables a deep understanding of a subject that, in its turn, improves students` ability to relate new knowledge with previous experiences or information; application - which helps to apply new information or skills in life situations, reflect on what has been studied and continue to develop problem-solving skills $[21,26]$.

5. A cognitive learning space that allows applying cognition to certain learning activities should be modeled in accordance with the key principles of cognitive learning. First, focus on what you know, rather than on the responses to stimuli. Second, emphasize order, structure and connections. Third, use active approaches, plans and profitability [9, $11,16]$.

6. The analysis and application of some types of cognitive learning methods and techniques (cooperative, collaborative, meaningful, associative, discovery learning, etc.) and cognitive tools (databases, semantic networks, expert systems, communications software, on-line collaborative knowledge construction environments, multimedia construction software, etc.) led us to conclusion about the evident benefits of cognitive 
learning for educational systems of the world, Europe, country, region, particular institution or a stakeholder $[9,10]$.

7. A well-organized learning space based on a cognitive approach can be equally beneficial for the entire educational landscape of a region or country, for the climate of a particular institution, for achievements and development of a particular student or a particular teacher and/ or researcher. Cognitive learning improves comprehension; it develops problem-solving and study skills; it promotes long-term learning; it sets enthusiasm and improves confidence; and, last and most important, it develops a lifelong love for learning [6, $13,14]$.

Modeling and design of the effective tech-based, information-rich and equitable cognitive learning space at university was provided with regard to mental needs and expectations of modern students attributed to "digital generation Z". The proposed structure is only a design model presented by the authors. This form of organization of the learning spaces seems timely and may serve as a start-up for training of students at university level.

\section{References}

1. I.N. Ainoutdinova, T.M. Tregubova, A.N. Khuziakhmetov, MJLTM, 7, 9/2, 431-444, (2017)

2. M. Warschauer, Learning Inquiry, 1, 1, 41-49 (2007)

3. M.B. Brown, J.K. Lippincott, Educause Quarterly, 26, 1, 14-16 (2003)

4. R. Maloy, CITE, 16, 2, 172-183 (2016)

5. E. King, M. Joy, J. Foss, J. Sinclair, J. Sitthiworachart, IETI, 52, 5, 522-535 (2015)

6. R. Kh. Gilmeeva, A. R. Kamaleeva, A. S. Katz, E. Y. Levina, and all. Cognitive pedagogy: teaching aid, 228 (2020).

7. UNESCO ICT Competency Framework for Teachers - ICT CFT (2011)

8. UNESCO 1999-2000 Report (1999)

9. B. Eickelmann, M. Vennemann, EERJ, 16, 6, 733-761 (2017)

10. N. Sampson, LLT, 7, 3, 103-118 (2003)

11. D. G. Oblinger, Learning Spaces, Educause, 444 (2006)

12. D. Cormier, Innovate: IJOE, 4, 5, 1-6 (2008)

13. N.D. Koletvinova, S.U. Bichurina, IEJME, 11, 4, 829-841 (2016).

14. M.G. Navarro, ATPP, 32, 1, 40-47 (2011)

15. J.D. Wake, O. Dysthe, S. Mjelstad, ET\&S, 10, 1, 40-51 (2007)

16. B. Ojose, TME, 18, 1, 26-30 (2008)

17. J. S. Bruner, Journal of Child Language, 2, 1-19 (1975)

18. A. Bandura, C. Barbaranelli, Child Development, 67", 3, 1206-1222 (1996)

19. M.Ul Hassan, R. Ali Akbar, NUML, 7, 2, 58-68 (2019)

20. A.T. Beck, Perspect. Psychol. Sci, 14, 1, 16-20 (2019)

21. S. Marginson, T. K. A. Dang, Asia Pacific Journal of Education, 37, 1, 1-14 (2016)

22. A. Acquah, E. Quainoo Jnr., JIEA, 7, 7, 1-4 (2017)

23. D. Villa, J. Dorsey, Research by CGK, Austin, Texas, USA, 30 (2017)

24. K.E. Kariippanon, D.P. Cliff, A.D. Okely, A.M. Parrish, J Sci Med Sport, 22, 8 (2019)

25. R. Talbert, A. Mor-Avi, Heliyon, 5, 12 (2019)

26. A. Đukić, Keeping up with technologies to create the cognitive city, 378 (2019)

27. D. L. Dinsmore, L.K. Fryer, PIBBS, 6, 2, 107-114 (2019) 